\title{
HACIA UN SEMINARIO DEL TERCER MILENIO
}

DOI: https://doi.org/10.52039/seminarios.v51i176.718

Autor: Vicente Zueco Vázquez. Sacerdote Operario Diocesano. Director del Instituto de Pastoral Vocacional de Buenos Aires (Argentina).

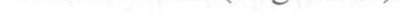

\section{CONSTATACIONES MOTIVADORAS}

Gresacke (Ser Sacerdote Hoy, Sígueme, Salamanca 2003. Pág. 461) hace algunas reflexiones, que si bien están centradas en la realidad de Alemania, pueden ser iluminadoras también para otras realidades:

\section{La preocupación por los sucesores}

"Cuando se ve cuántas comunidades tienen problemas con sus sacerdotes y que a menudo sólo a duras penas les aguantan; cuando se comprueba cuántos sacerdotes no se sienten hoy día a la altura de sus obligaciones y, por tanto, se sienten terriblemente desdichados y eso les aboca a mantener una doble vida o a renunciar a su ministerio; cuando en algunas diócesis hay un elevado porcentaje de sacerdotes que abandonan su 
ministerio, o cuando en casi todas las diócesis hay una serie de sacerdotes jóvenes que después de dos o tres años de dedicarse intensamente a sus tareas, con no raras veces elogio general, dejan el sacerdocio, entonces lo apropiado será que muchos responsables «pongan a punto el despertador», es decir, estén más atentos a las condiciones de admisión. Precisamente porque las comunidades tienen derecho a esperar que se les proporcionen sacerdotes que ejerciten su ministerio con arreglo al evangelio, y precisamente porque es de desear que los sacerdotes, a pesar de todas las dificultades que encuentren en su profesión, sientan realizada su vida y experimenten gozo y paz interior, y no terminen en tragedia, debe señalarse claramente a los candidatos que a la vocación sacerdotal, en la perspectiva de las condiciones actuales y de las que se plantearán a medio plazo, están asociadas grandes exigencias, y que, por tanto, no debe ser admitido sin más a las sagradas órdenes cualquiera que piense de sí mismo (o de quien otros piensen) que tiene vocación sacerdotal.

Por consiguiente, no basta orientarse-como se hacía antes-por las circunstancias existentes. Demasiadas circunstancias han cambiado hoy día y seguirán cambiando. El sacerdote del futuro tendrá que situarse más intensamente que antes dentro de la comunidad del pueblo de Dios, sobre todo colaborando con los laicos, delegando responsabilidades, practicando la adopción conjunta de decisiones, no relacionándose con los colaboradores laicos como lo haría un jefe que pretenda estar más enterado de todo o poseer privilegios, sino tratando con ellos con fina sensibilidad «espiritual»: como un hermano entre hermanos y hermanas que se hallan en una comunidad en la que hay diferentes vocaciones ${ }^{1}$. Con esto queda dicho que el sacerdote en el futuro tendrá que tener más sentido comunitario y mayor capacidad de comunicación, y eso con una intensidad muchísimo mayor que antes. Tendrá que estar "presente» - mucho más que ahora- entre los hombres, y no deberá vivir ya una existencia privilegiada, como la que se le inculca actualmente (de manera «no expresa») desde el primer día de su estancia en el seminario, enseñandole que él no tiene que realizar el servicio militar ni una prestación civil, que no ha de preocuparse de buscar vivienda ni tiene que angustiarse por ganarse la vida. Y es que el «señor» seminarista es "canela

1 Cf. J. Freitag, Sakramentale Sendung. Gabe und Aufgabe des sacramentum ordinis, edit. por el Informationszentrum Berufe der Kirche, Freiburg i.Br. 1990. 
fina». Las cosas no pueden ni podrán seguir así, ni por lo que respecta a los seminaristas ni por lo que respecta a los sacerdotes. Suponemos que el «tributo eclesiástico» (existente en Alemania y en algunos otros países europeos) no podrá mantenerse en las condiciones actuales. Y una Iglesia que se va haciendo cada vez más pequeña dependerá de los donativos - más o menos voluntarios- que aporten los fieles. Y por tanto, el sacerdote no podrá permitirse ya en el futuro el lujo de disponer de una casa parroquial bien amueblada y con todos los equipamientos, que son los signos externos del estado burgués de un "reverendo» y que, por lo demás, le protegen de mantenerse realmente presente entre los hombres. No, sino que tendrá que vivir entre sus hermanos y hermanas en uno de los pisos de los bloques de apartamentos, en viviendas de protección oficial, en viejos caserones alquilados y en residencias. Michael N. Ebertz, especialista en sociología de la religión, ve de esta misma manera el futuro del ministerio eclesiástico. En una entrevista, señalaba: el futuro sacerdote será «un trabajador de a pie más que un católico de posición acomodada, un proletario más que un propietario de un chalé con jardín y piscina». Lo que esto significa podemos verlo ya por la vida que lleva el clero del Tercer Mundo (América latina), pero también en Francia. Allí gran parte del clero vive con el salario mínimo o por debajo del salario mínimo, es decir, vive en un nivel de precariedad. El sacerdote del futuro, si no precisamente en el umbral de la pobreza, vivirá desde luego muy modestamente, y además tendrá que arreglárselas para ser el responsable de una Iglesia que, en su núcleo, constituye una minoría nada atractiva. Todo esto habrá que describírselo, sin disimulos, al candidato al ministerio, aunque nadie pueda predecir con absoluta certeza si las cosas van a ser exactamente así o de otra manera.

En todo caso, nos hallamos - como se ha mostrado- ante un fundamental cambio de la Iglesia y del ministerio. Y por eso es de la máxima importancia no despertar o permitir que exista en quienes se preparan para la profesión sacerdotal el menor vestigio de ilusiones engañosas, ni describir a medias tintas las condiciones previas para recibir la ordenación sacerdotal, ni siquiera teniendo en cuenta lo que se ha dado en llamar la «escasez de sacerdotes». Acerca de este tema convendría meditar lo que se dice en el capítulo 7 del libro de los Jueces; «El Señor dijo a Gedeón; 'Tu gente es demasiado numerosa para que yo les entregue Madián. Israel podría gloriarse ante mí, diciendo: Mi propia fuerza me ha librado. Por 
eso, reúne al pueblo y dile: El que tenga miedo y tiemble, que se vuelva». Entonces se volvieron de hecho veintidós mil, y quedaron todavía diez mil. Entonces habló de nuevo el Señor a Gedeón: «Todavía son demasiados...". Finalmente le agradó al Señor salvar a Israel con un pequeño grupo de personas, pero que estaban dispuestas a entregarse de lleno. Y no quiso servirse de personas dispuestas a medias, pero que por cualesquiera razones querían participar en la lucha.

Así que la preocupación por los sucesores es una cuestión de dos facetas. Por un lado, hay que mantener alejados del ministerio a los que presuntamente, en las circunstancias actuales, no estén a la altura del sacerdocio. Por otro lado, hay que buscar con todas las energías sucesores que sean adecuados. Por eso, la preocupación es un asunto que está profundamente asociado con la esencia del ministerio. Porque todo ministro se halla en la sucesión apostólica y necesita, por tanto, un sucesor. Pero si la llama de la vida se inflama en la vida misma, entonces habrá que preguntar a la propia vida sacerdotal si de ella dimanan impulsos que atraigan y propaguen la vocación. Asimismo, en el sacerdote tendrá que verse que el reino de Dios es «el tesoro escondido en el campo» y "la perla preciosa" por la que hay que entregar todo lo que se tiene, no con la actitud de una sombría y triste renuncia, sino con la alegre certeza de estar consiguiendo algo mucho mejor. El estar profundamente subyugado por Jesucristo y por su evangelio, y el sentirse fascinado por la vocación a la misión, apremia a entregarse «con toda alegría», como se dice en la sagrada Escritura; a jugárselo todo a una sola carta. Y precisamente que el evangelio es en verdad fascinante, algo por lo que vale la pena empeñarlo todo, habrá que verlo palpablemente en la vida del sacerdote y constituirá también un gran atractivo para sus potenciales sucesores."

La revista "Criterio" de Buenos Aires, en su No 2293, de Junio de 2004 trae un artículo que llama poderosamente la atención por estar escrito por una persona ajena al mundo clerical, pero que refleja las inquietudes de muchos laicos con relación a la selección y formación de los sacerdotes. Lo hace desde la perspectiva de la Iglesia de JUL de la que forma parte:

\section{La crisis de la Iglesia en los Estados Unidos Frederick W. Gluck (New York) ${ }^{2}$}

\footnotetext{
${ }^{2} \mathrm{El}$ autor fue director y gerente de las McKinsey \& Co., y vicepresidente del directorio y director de The Beachtel Group.
} 


\section{El estado actual}

"Consideraré el estado actual de la Iglesia desde la perspectiva de un consultor de gestión. Observaré los recursos humanos, las finanzas, la gestión general y el posicionamiento en el mercado.

1. Existen dos problemas que atañen en general a los recursos humanos en la Iglesia: talento insuficiente y procesos inadecuados para administrarlo.

Específicamente, en cuanto al talento:

- Envejecimiento rápido de la fuerza laboral;

- Drástica disminución de la capacidad de reclutamiento de la Iglesia en los últimos cuarenta años; llantes;

- La Iglesia ya no es la primera opción de los mejores y los más bri-

- La gente de Iglesia está desmoralizada debido a los conflictos internos y al escándalo público.

Respecto del proceso:

- Muchos creen que las políticas de personal de la Iglesia son abiertamente restrictivas y contraproducentes;

- No existe un sistema de evaluación de desempeño efectivo en ningún nivel, lo cual torna muy difícil, si no imposible, planificar o implementar oportunamente un cambio constructivo;

- No existe un mecanismo de planificación efectivo en marcha para abordar los cambios drásticos a raíz de la combinación de clérigos y laicos en posiciones importantes dentro de la Iglesia y de la red de servicios sociales relacionados, que ya ha comenzado y es inevitable que continúe. Esto también complica el proceso de cambio;

- En tanto los aportes de los laicos a la administración y la gestión de los asuntos eclesiales ya son bastante importantes -lo serán cada vez más-, no se advierte un plan general para una integración fluida.

En suma, la Iglesia parece carecer de los elementos mismos de un proceso o un sistema efectivo para la gestión de recursos humanos en un momento en que la necesidad es enorme y creciente." 
Estos dos testimonios ponen de manifiesto alguna de las realidades que cuestionan nuestra pastoral vocacional y los procesos formativos. Es tiempo de creatividad. El mismo Juan Pablo II en su libro "Don y misterio" dice "El sacerdote, con toda la Iglesia, camina con su tiempo y es atento oyente atento y benévolo pero a la vez crítico y vigilante de lo que madura en la historia".

Vemos que el modelo de sacerdote que presenta para el futuro su Exhortación Apostólica Pastores dabo vobis, está representado por el icono del pastor entregado al cuidado del rebaño e impulsado, como Jesús, por la caridad pastoral. El amor de pastor constituye el contenido esencial y específico del alma del sacerdote: "La caridad pastoral es la virtud por la cual imitamos a Cristo en su donación y servicio. No es sólo lo que nosotros hacemos, sino la donación de nosotros mismos lo que manifiesta el amor de Cristo a su rebaño. La caridad pastoral determina nuestro modo de pensar y actuar, nuestra manera de relacionarnos con la gente" (PDV 23).

Delineado así el modelo de sacerdote, es importante precisar el modelo educativo que contemple las cuatro dimensiones que presenta la PDV: la humana, la espiritual, la intelectual y la pastoral. En el $N^{\circ} 57$ dice: "Toda formación de los candidatos al sacerdocio está orientada a prepararlos de una manera específica para comunicar la caridad de Cristo, buen pastor. Por tanto, esta formación, en sus diversos aspectos, debe tener un carácter esencialmente pastoral".

El Concilio de Trento tuvo que responder a una serie de necesidades coyunturales de la Iglesia. No fue la menor de todas la reforma del clero. Dentro de este objetivo los Seminarios llamados "Conciliares" fueron los que a lo largo de los siglos subsiguientes facilitaron el logro de esta prioridad de la contrarreforma.

Con la llegada del Vaticano II se tuvo la impresión de que el Seminario Conciliar había cumplido un ciclo y se ensayaron todo tipo de modelos de formación con desigual acierto: Pequeñas comunidades, pisos, comunidades insertas... De todas ellas se han sacado experiencias valiosas, y la convicción de que detrás de cada una de las experiencias había una concepción de Iglesia, de ministerio y de vocación que no siempre estaba suficientemente reflexionada y formulada.

En éstos últimos años se ha producido un aumento considerable de vocaciones para el clero secular, incluso en Europa. Pero las crecientes 
deserciones de sacerdotes jóvenes en los cinco primeros años después de la ordenación, hacen pensar en que la formación que proporcionan nuestros seminarios no es la adecuada. Se tiene la impresión de que faltaría una reflexión más profunda y algunos ensayos mejor planificados para llegar a un nuevo paradigma de seminario que, a semejanza del Seminario Conciliar Tridentino, fuese un intento del Seminario del Concilio Vaticano II.

\section{MARCO DE LA REALIDAD}

Aunque estas apreciaciones tienen el respaldo de algunas evaluaciones hechas por formadores, obispos y pastoralistas no pretenden ser un diagnóstico científico de la situación de los seminarios. Pero podemos aventurar que:

Entre los seminaristas se percibe una cierta insatisfacción porque sus necesidades vitales y sus aspiraciones con relación al futuro ministerio no encuentran respuesta suficiente por parte del seminario. Por eso se sienten, a veces ajenos a la institución. Siguen utilizándose pedagogías pensadas para adolescentes, cuando la gran mayoría de los seminaristas está rondando los 30 años.

Entre los educadores y profesores se nota que viven insatisfechos con el seminario actual, con el tipo de formación, con los resultados, con la estructura del mismo. Cada uno busca a quien atribuir la causa del malestar. A veces da la impresión de que los seminaristas en lugar de evolucionar, involucionan. Se perpetúan en la etapa formativa y al ser ordenados mantienen los reflejos que llaman de "adultescentes".

Entre los sacerdotes de las diócesis, se tiene la sensación de que el seminario actual no responde en gran parte a las expectativas de la Iglesia local; los sacerdotes que salen del seminario están distantes psicológica, mental y espiritualmente de la vida de la gente. En todas las profesiones hay un tiempo largo de adaptación y prácticas que garantizan la inserción del profesional en el ámbito de trabajo.

Entre los agentes de pastoral existe la misma sensación de que los nuevos sacerdotes no responden a las expectativas de los agentes más comprometidos en las diferentes pastorales; los sienten distantes y hasta autoritarios. No promueven la comunión entre los diferentes ministerios y carismas. Siguen con la mentalidad de una Iglesia uniministerial. El sacer- 
dote es el único que sabe, que puede y que hace. Los otros ministerios, aun el Diaconado, son prescindibles. Se rompe así la ecología ministerial. La primera consecuencia: el ministerio presbiteral puede convertirse en una especie protegida.

Entre los fieles en general tampoco se da una aceptación del estilo de sacerdote nuevo que lo consideran un tanto distante y a veces ajeno a sus problemas.

\section{PROPUESTA FORMATIVA}

Frente a esta percepción de nuestros seminarios clásicos hay ensayos de otro tipo de seminarios que se están realizando en diferentes ámbitos eclesiales. En muchos de ellos campea una idea fuerza: "Los candidatos al presbiterado, al diaconado permanente y a otros ministerios instituidos o confiados a los laicos se han de formar en un seminario concebido como proceso formativo, como comunidad formativa ministerial, vivido en comunidades parroquiales, en comunión con la Iglesia Local y Universal".

Los valores que deberían inspirar estas comunidades serían: La libertad de los hijos de Dios que garantice la autenticidad y madurez de las motivaciones, la contemplación como espacio para internalizar los valores evangélicos y ministeriales, la comunión eclesial con el presbiterio y los diferentes carismas y estructuras, la caridad pastoral y el ser servidores de un pueblo de servidores.

\section{EL OBJETIVO FINAL}

A lo largo de diferentes etapas formativas a planificar, que tengan en cuenta la formación de los candidatos en la dimensión humana, espiritual, comunitaria, intelectual y pastoral, se trataría de lograr: "Servidores o ministros que sean signo e instrumento de unidad y de la misión de la Iglesia Particular en comunión con la Iglesia Universal". "Profetas, sacerdotes y ministros de la unidad, conformados a Cristo Siervo como cuerpo ministerial de la Iglesia Local". 
EL SEMINARIO DE CÓRDOBA (Argentina). Un proyecto de formación en medio de la comunidad parroquial.

Providencialmente ha caído en mis manos el proyecto que la Arquidiócesis de Córdoba (Argentina) ha preparado para comenzar en el curso del 2005. Me parece un intento serio en esta dirección. Voy a transcribir los conceptos que me parecen más interesantes:

\section{Proyecto de reestructuración de los últimos años de la Formación Inicial}

\section{Descripción}

Manteniendo la unidad de la formación inicial en el Seminario, proponemos reestructurar los tres últimos años, de la siguiente manera:

El segundo y el tercer año de la teología integrarán una comunidad formativa, a cargo de uno de los miembros del Equipo de Formadores del Seminario, dentro del marco de una comunidad parroquial, vinculada a su vida pastoral.

En el cuarto año de la teología, en cambio, proponemos que cada seminarista sea asignado a una parroquia, a fin de que viva en la casa parroquial, conviviendo con el párroco y compartiendo desde dentro con la comunidad cristiana. En este contexto, continúa su formación, bajo la guía y conducción del Seminario y con el cercano acompañamiento del párroco. Sería deseable que esta parroquia fuera la misma en la cual, al año siguiente, ejercite su Acolitado y se prepare inmediatamente para la ordenación diaconal y el inicio de su ministerio.

\section{Fundamentación}

Actualmente, quienes se preparan para el sacerdocio ministerial en nuestro Seminario lo hacen en el marco de la vida en común dentro de la casa del Seminario, con las variantes y matizaciones que requieren las diversas etapas del itinerario formativo. Reconocemos el valor de este estilo de vida, principalmente en los primeros años, puesto que crea las condiciones que permiten el desarrollo de la vida espiritual, en un clima comunitario ordenado, de recogimiento y reflexión, junto con un más profundo autoconocimiento y reconocimiento de las propias motivaciones, 
indispensables para el discernimiento vocacional; dichas condiciones, favorecen, también, la actitud discipular de docilidad a la acción de la gracia, por la obediencia cordial a las mediaciones formativas.

Como expresa Pastores dabo vobis (n. 60): "La necesidad del Seminario Mayor -y de una análoga Casa religiosa de formación- para la preparación de los candidatos al sacerdocio, como fue afirmada categóricamente por el Concilio Vaticano II (cf. Decreto sobre la Formación sacerdotal Optatam totius, 4), ha sido reiterada por el Sínodo con estas palabras: "La institución del Seminario mayor, como lugar óptimo de formación, debe ser confirmada como ambiente normal, incluso material, de una vida comunitaria y jerárquica, es más, como casa propia para la formación de los candidatos al sacerdocio, con superiores verdaderamente consagrados a esta tarea. Esta institución ha dado muchísimos frutos a través de los siglos y continúa dándolos en el mundo" (Propositio 20).

No obstante, como el mismo texto afirma a continuación, hay que reconocer que "el seminario, que representa como un tiempo y un espacio geográfico, es sobre todo una comunidad educativa en camino". Y explicita enseguida para mayor claridad: "La comunidad promovida por el Obispo para ofrecer, a quien es llamado por el Señor para el servicio apostólico, la posibilidad de revivir la experiencia formativa que el Señor dedicó a los Doce... La identidad profunda del seminario es ser, a su manera, una continuación en la Iglesia, de la íntima comunidad apostólica formada en torno a Jesús, en la escucha de su Palabra, en camino hacia la experiencia de la Pascua, a la espera del don del Espíritu para la misión. Esta identidad constituye el ideal formativo que -en las muy diversas formas y múltiples vicisitudes que como institución humana ha tenido en la historia- estimula al seminario a encontrar su realización concreta, fiel a los valores evangélicos en los que se inspira y capaz de responder a las situaciones y necesidades de los tiempos".

En el n. 61, Pastores dabo vobis añade que «la labor educativa debe saber conciliar armónicamente la propuesta clara de la meta que se quiere alcanzar la exigencia de caminar con seriedad hacia ella, la atención al "viandante", es decir al sujeto concreto empeñado en esta aventura y, consiguientemente, a una serie de situaciones, problemas, dificultades, ritmos diversos de andadura y de crecimiento. Esto exige una sabia elasticidad (...) Esto vale no sólo respecto a cada una de las personas, sino también en relación con los diversos contextos sociales y culturales en los que se des- 
envuelven los Seminarios y con la diversa historia que cada uno de ellos tienen. En este sentido la obra educativa exige una constante renovación» (los textos destacados en cursiva son del original).

Precisamente, éstas motivan a revisar el esquema formativo actual y a proponer algunos cambios, como respuesta a lo que los formadores en diálogo con los seminaristas y los sacerdotes de la Arquidiócesis, desde hace ya varios años veníamos verificando.

Así como se reconoce la necesidad de un tiempo inicial de formación en las condiciones antes señaladas, para el discernimiento y respuesta iniciales a la vocación sacerdotal, así también se advierte que, pasados unos años, otras condiciones resultan indispensables para su mejor desarrollo. En efecto, la prolongación de aquellas condiciones formativas, inicialmente necesarias y provechosas, lleva en no pocos casos a la pérdida del horizonte y empuje evangelizador con el que el seminarista comenzó su formación; genera cierto estancamiento del propio desarrollo, que disminuye el trabajo interior y amengua la tensión hacia el crecimiento; insensiblemente establece una inevitable distancia entre la vida habitual del seminarista y la del pueblo de Dios y la sociedad en general, con la consecuente pérdida de realismo, creciente riesgo de aburguesamiento, desplazamiento hacia una espiritualidad desencarnada; las relaciones y situaciones, acotadas y protegidas, en que se desenvuelve, dificultan la adecuada percepción de sí mismo, de sus posibilidades y límites, frente a la vocación, y favorecen el idealismo, el autoengaño y la huida de las confrontaciones necesarias para el crecimiento personal.

Un espacio formativo más próximo a las condiciones reales en que se desarrolla habitualmente el ministerio sacerdotal parece más propicio a la doble finalidad propuesta de favorecer un discernimiento más ponderado y por lo mismo, más libre y personal, por el sacerdocio, ya la de introducir progresivamente a la persona en el servicio pastoral de la Iglesia.

Con esta propuesta, pues, pretendemos producir las modificaciones concretas que la realidad desde la experiencia aconseja, a fin de realizar fielmente el «ideal formativo» que propone Pastores dabo vobis. Manteniendo firmemente la necesidad del seminario como ambiente formativo de los futuros sacerdotes, se impone concebirlo -siguiendo al mismo documento (n. 60)-, más que como un espacio físico, como "una experiencia original vida de la vida de la Iglesia; en él el Obispo se hace presente a través del ministerio del rector y del servicio de corresponsabilidad y de comunión 
con los demás educadores, para el crecimiento pastoral y apostólico de los alumnos". Pensamos que las experiencias que esta propuesta alienta han de ser presentadas y vividas como integrando al seminario, en cuanto espacio de la formación de los futuros sacerdotes. Las pensamos integradas a la comunidad educativa del seminario, y por lo tanto, "al servicio de un programa claramente definido que, como nota característica, tenga la unidad de dirección, manifestada en la figura del Rector y sus colaboradores, en la coherencia de toda la ordenación de la vida y actividad formativa y de las exigencias fundamentales de la vida comunitaria, que lleva consigo también aspectos esenciales de la labor de formación. Este programa debe estar al servicio - sin titubeos ni vaguedades-de la finalidad específica, la única que justifica la existencia del seminario, a saber, la formación de los futuros presbíteros, pastores de la Iglesia" (PDV 61).

Tal como lo presenta Pastores dabo vobis el seminario "antes que ser un lugar o un espacio material, debe ser un ambiente espiritual, un itinerario de vida, una atmósfera que favorezca y asegure un proceso formativo, de manera que el que ha sido llamado por Dios al sacerdocio pueda llegar a ser, con el sacramento del Orden, una imagen viva de Jesucristo Cabeza y Pastor de la Iglesia" (n. 42), mediante el seguimiento de Jesucristo, como los Apóstoles, reviviendo, de alguna manera, la experiencia original de aquellos Doce a quienes Jesús 1lamó, "para que estuvieran con él" y para enviarlos a predicar (cfr. Mc 3,14; PDV 60). Los evangelios nos muestran cómo Jesús los fue preparando para la misión mediante el compartir de su propia vida, en una relación personal profunda; les comunicó su enseñanza, los fue educando, no sólo con palabras (cf. Mc 4,10-12 .33-34), sino también haciéndolos testigos de signos y acontecimientos reveladores de su identidad y de su misión, cuyo significado les ayuda a comprender (cf. Mc 3,7-12; 4,35-41), y haciéndoles pasar por diversas experiencias en las que, de manera activa y directa, pudieran reconocer el poder de quien los llamó y sus propias limitaciones (cfr. Mc 6,7-13.30-44; 8,14-21; 9,2-8). Las múltiples situaciones cotidianas de la convivencia brindan a Jesús la ocasión oportuna para ayudarles a crecer en la respuesta (cfr. Mc 9,33-40; $10,13-16.23-27.32-45 ; 12,41-44 ; 13,1-2$ ). La presencia y la participación de los discípulos en los acontecimientos decisivos de la pasión, muerte y resurrección de Jesús, será la experiencia fundamental y constitutiva de la misión para la cual el Señor los fue pacientemente preparando y en la cual los acompañó "colaborando con ellos" (cfr. 16,9-20). 
Estos textos, y muchos otros pasajes del Nuevo Testamento (particularmente, los escritos paulinos, con su marcado acento apostólico), nos ayudan en la búsqueda de las claves de renovación de la formación sacerdotal. Entre otras cosas, nos enseñan que la formación para el ministerio apostólico pasa por una personal relación con Jesús vivo, la experiencia de su amor, de su elección; que ha ser claramente experiencial y no meramente teórica, aprovechándose del valor pedagógico de las situaciones de la convivencia, de los contextos y acontecimientos, interpretados a la luz del evangelio, buscando discernir en ellos la voluntad de Dios; que una condición indispensable es que los "discípulos" se involucren activamente en el proceso formativo y que los formadores generen las condiciones para que libremente abracen el llamado; etc.

\section{Finalidad}

Con la propuesta de reestructuración de los últimos años de la formación perseguimos una doble finalidad:

1) Generar condiciones que favorezcan el carácter libre y personal de la opción vocacional como fruto de un auténtico proceso de discernimiento.

Un estilo de vida más próximo al que efectivamente llevan los presbíteros, y en contacto directo con las diversas vocaciones, dones y carismas de una comunidad parroquial, las relaciones interpersonales, las situaciones y acontecimientos que tal experiencia permite, con el adecuado acompañamiento de los formadores, parece favorecer la maduración de un discernimiento más realista de las propias motivaciones y posibilidades en orden a la opción por el sacerdocio.

2) Crear las condiciones que permitan a los futuros pastores asumir serena y progresivamente las responsabilidades y exigencias propias de la vida y el ministerio presbiteral.

Advertimos que para ir configurándose con la persona y las actitudes, gestos y opciones propias de Jesús Buen Pastor, es pedagógicamente relevante que los seminaristas se encuentren de modo realista con las situaciones, los desafíos, las dificultades y la vida cotidiana de los sacerdotes. 


\section{Objetivos por comunidades}

$2^{\circ}$ de Teología:

- Integrarse progresivamente como comunidad formativa a la comunidad más amplia de la parroquia.

- Asumir paulatinamente las características propias de la experiencia como una riqueza y una oportunidad formativa (en todas las dimensiones de la formación y afirmando su profunda vinculación).

- Continuar el proceso de discernimiento vocacional que se venía desarrollando, confrontando de manera realista las propias capacidades con las exigidas por la vida sacerdotal en orden a una decisión libre y personal (a fines de este año podría tener lugar la Admisión).

$3^{\circ}$ de Teología:

- Consolidar el discernimiento y la opción vocacional expresados en la Admisión.

- Familiarizarse con la Palabra como fuente animadora de la vida y el ministerio pastoral en el seno de la comunidad (a fines de este año podría tener lugar el Lectorado).

- Desarrollar la capacidad de integrar equilibradamente las diversas exigencias de la formación (en el campo de lo humano, espiritual-teologal, intelectual-cultural, fraterno-comunitario, carisma diocesano) respondiendo a ellas serena y flexiblemente.

- Iniciarse en las actitudes pastorales fundamentales de la escucha de la realidad, el discernimiento a la luz de la fe y el acompañamiento de los procesos personales y comunitarios.

$4^{\circ}$ de Teología:

- Progresiva identificación con la espiritualidad, el ministerio y el estilo de vida propios del sacerdote secular.

- Integrarse cordialmente a la comunión presbiteral, mediante el cultivo de la fraternidad sacerdotal y la participación en las diversas instancias de encuentro.

- Abrazar cada vez más consciente, libre y gozosamente las exigencias de la consagración, el celibato y la caridad pastoral, en vinculación estrecha con el misterio eucarístico (a fines de este año podría tener lugar el Acolitado). 
- Afianzar el reconocimiento personal de la necesidad de la formación integral permanente y el hábito de poner los medios para ello como exigencia de fidelidad a la gracia de la vocación.

- Desarrollar las actitudes que permitan una satisfactoria expresión de la afectividad acorde a las condiciones de la vida sacerdotal, integrando exigencias ministeriales, soledad, vínculos de amistad, familiares, eclesiales, etc.

- Crecer en capacidad de vivir la corresponsabilidad eclesial, de diálogo, de trabajo en equipo, de compromiso con la nueva evangelización, en un estilo de participación y comunión orgánica, dentro de las líneas pastorales de la Iglesia, bajo la conducción pastoral del obispo.

\section{Perfil de la Comunidad Parroquial y del Párroco}

(Aquí describen el perfil de la parroquia y del párroco que han de congeniar con los objetivos de esta etapa del seminario y con el proyecto de Diócesis que subyace en él.)

\section{Estilo de vida de los formandos en Parroquia}

\section{La comunidad formativa en parroquia}

La comunidad formativa en parroquia es parte del Seminario y, por lo tanto, desarrolla su vida en sintonía con sus orientaciones formativas, bajo la guía y con el acompañamiento cercano del formador a cargo. Estando dentro de la comunidad parroquial, guardará, sin embargo, en cuanto casa de formación, una cierta autonomía, necesaria para la consecución de sus objetivos específicos, con su ritmo, sus tiempos y sus espacios, incluso materiales, distintos de los de la casa parroquial. Mediante un constante discernimiento, animado por el formador, la comunidad procurará la equilibrada integración de las actividades específicas de la formación inicial y las propias de la pastoral parroquial.

El formador propio e inmediato de esta comunidad es el miembro del equipo de formadores del Seminario designado a tal efecto, y como tal ha de ser reconocido claramente por los seminaristas; el párroco desempeña, indudablemente, un rol formativo relevante, en cuanto 
asociado a la función del equipo de formadores, sobre todo, mediante el testimonio de su vida. Como guía y pastor de la comunidad cristiana, el párroco, junto con el formador asignado, distribuirá, acompañará y evaluará las diversas formas de participación de los seminaristas en la actividad pastoral de la parroquia.

Algunos valores formativos presentes en la formación actual del Seminario, por la importancia que se les reconoce, deberán mantenerse y cultivarse en la vida de la comunidad de seminaristas en la parroquia, como por ejemplo:

- La disponibilidad discipular a la propuesta formativa del Seminario en general y, concretamente expresada por las orientaciones del formador a cargo de la comunidad.

- Capacidad de recogimiento, orden y disciplina en la vida diaria.

- Espiritualidad de comunión vivida en lo cotidiano.

- Mirada de fe de la realidad para reconocer los "signos de los tiempos".

- Crecer en la libertad responsable a partir de la aplicación de los criterios de discernimiento.

- Atención a las exigencias propias de las dimensiones de la formación para el sacerdocio (humana, teologal-espiritual, intelectual-cultural, fraterna-comunitaria), con la necesaria dedicación de tiempo y esfuerzo.

- Conocer, valorar y cultivar lo propio del carisma y la espiritualidad del sacerdote secular.

Aspiramos a que este nuevo estilo formativo favorezca la consolidación de otros valores, que dé lugar a aportaciones formativas propias, como, por ejemplo:

- El protagonismo del muchacho en su propia formación, que lo lleve a asumirla más decididamente en primera persona.

- Mirada realista sobre sí mismo que favorezca un discernimiento vocacional más adecuado.

- Reciedumbre y capacidad de sacrificio en la realización de los compromisos.

- Un estilo cotidiano de vida más responsable y austero, menos cómodo y "aburguesado".

- Ejercitarse en la corresponsabilidad, el diálogo y el trabajo en equipo. 
- Un ambiente más familiar, que permita unas relaciones interpersonales afectivamente más cálidas y enriquecedoras.

- Valoración de la vida del Pueblo de Dios en su rica variedad de dones y vocaciones desde un compartir más cotidiano, cercano.

- Un aprendizaje pastoral gradual, situado y experiencial.

- Progresiva y acompañada aproximación a la vida y ministerio de los sacerdotes, que permita iniciar el ministerio después de la ordenación de modo menos abrupto.

- Ensayar concretamente el "modo de estar en el mundo" propio del consagrado.

\section{El seminarista del último año de la formación en parroquia.}

La vida en parroquia del seminarista del último año es decididamente parte de la formación inicial que ofrece el Seminario.

Por lo tanto, el estilo de vida de este seminarista, integrado a la comunidad parroquial y conviviendo cotidianamente con el párroco, estará caracterizado por una referencia habitual y asidua a los formadores del Seminario, a las orientaciones y a algunas actividades de las que convenga que participe.

El párroco, en esta experiencia, es asimilado a los formadores del equipo, y como tal debe ser reconocido por el seminarista. Serán responsabilidades del párroco las de acompañar al seminarista en su camino de formación, guiándolo desde su experiencia y su saber, ayudando al discernimiento vocacional en constante comunicación y diálogo con el Rector y los demás miembros del equipo de formadores del Seminario.

Esta experiencia debería aportar ciertos valores formativos propios, tales como:

- Autonomía personal para vivir la fidelidad a las exigencias de la vocación como expresión de libertad responsable (administración ponderada del tiempo en orden a integrar en la trama diaria de la vida en una comunidad parroquial, la vida espiritual, la oración; el estudio; las relaciones fraternas el deporte y la recreación; etc.).

- La capacidad de vivir serena y equilibradamente la soledad inherente a la opción por el celibato.

- El cultivo de las relaciones fraternas con el presbiterio diocesano. 


\section{Vinculaciones con la comunidad educativa total del Seminario}

Puesto que quienes realicen estas experiencias son parte de la comunidad del Seminario Mayor, mantendrán múltiples vínculos y estarán en comunicación permanente con todas las personas que la conforman, harán suyo el ideario y las propuestas que les conciernen, y participarán de diversas actividades en común. En una palabra, deberán cultivar el sentido de pertenencia al Seminario; por su parte, los demás integrantes, tendrán que considerarlos así, realmente perteneciendo y formando parte de la comunidad, aun cuando residan fuera de la casa central. Esto supone ampliar el concepto de Seminario: abandonando su identificación con un edificio, concebirlo como el espacio formativo que la Iglesia local dispone y ordena para preparar, en la etapa inicial, a sus sacerdotes.

Este sentido de pertenencia al Seminario requerirá, por parte de estos como de todos los seminaristas, la adhesión cordial a su proyecto formativo, al espíritu que lo anima, a sus orientaciones. Particular cuidado se tendrá en disponer los medios para asegurar el necesario diálogo regular con el rector, el formador de comunidad directamente asignado, y el director espiritual del Seminario. Como todos los seminaristas, también quienes se encuentren en esta etapa formativa, continuarán con las entrevistas periódicas con su propio director espiritual, elegido de entre aquellos designados por el obispo.

La participación habitual en las clases y demás actividades académico-pedagógicas promovidas por el director de estudios, permitirá que los seminaristas prosigan su formación intelectual-cultural, y será el espacio natural para el contacto con los profesores y los demás estudiantes.

Las relaciones fraternas con todos los seminaristas serán cultivadas de diversas maneras, informales y organizadas, particularmente mediante encuentros y convivencias.

La integración a una misma comunidad formativa se expresará también por la participación en algunas actividades comunes a todos o parte de los formandos. Aunque para determinar estas actividades habrá que tener en cuenta múltiples circunstancias y será necesaria una constante evaluación y revisión, inicialmente consideramos que deberían incluirse:

- Los ejercicios espirituales anuales (marzo-septiembre) y los retiros mensuales.

- La convivencia anual de los seminaristas de Córdoba en Los Molinos, en febrero. 
- Las clases y otras convocatorias relativas a la formación intelectual.

- Actividades diocesanas en las que se requiera la presencia de la comunidad del Seminario (como por ej., la celebración de la Virgen Patrona, las Jornadas Pastorales, etc.).

- Talleres de formación pastoral.

- Celebraciones y acontecimientos propios de la vida del Seminario.

- Reuniones generales con todos los seminaristas.

\section{Puntualizaciones importantes}

Para asegurar, que estás sean experiencias formativamente positivas, será necesario que los formadores expliciten y los seminaristas conozcan claramente sus fundamentos, su sentido y sus objetivos, antes de iniciarlas.

Cada seminarista, además en diálogo con su formador, identificará los desafíos formativos, las tareas y objetivos para el año, teniendo en cuenta las características peculiares de la experiencia y procurando aprovecharlas. Este material (que puede integrarse adecuadamente con el PPV) será de referencia permanente en el diálogo formativo con quien corresponda.

La evolución de la experiencia en su conjunto, y de cada seminarista en particular, tendrá, que ser constantemente acompañada, observada, corregida y orientada por el equipo de formadores, y evaluada oportunamente en orden a su perfeccionamiento.

\section{Sostenimiento Económico}

El sostenimiento económico de esta nueva modalidad formativa estará incluido dentro del presupuesto general del Seminario, puesto que se trata de actividades que se requieren para el cumplimiento de su misión y la consecución de sus fines propios. Caben, no obstante, algunas especificaciones relativas a las dos formas de realización:

1. Comunidad formativa con un formador a cargo, vinculada a una parroquia

El economato del Seminario se ocupará de proveer todo lo necesario para su adecuado desenvolvimiento. Bajo la responsabilidad del formador 
a cargo, esta comunidad dispondrá de una "caja chica" para atender a sus necesidades ordinarias, que administrará de acuerdo a las indicaciones y bajo la supervisión del ecónomo del Seminario. Por razones no sólo de organización económica, sino estrictamente formativas, se procurará educar a los seminaristas que la integren en el sentido de la corresponsabilidad también en este aspecto, invitándolos a sentir como propia la economía de la casa, y a aportar en la forma y medida que puedan.

Con este espíritu se los invitará a comprometerse con las diversas iniciativas, en curso y/o que pudieran crearse, para generar recursos a favor del Seminario. En dialogo con el formador, atentos a no descuidar ningún aspecto importante de la formación, se considerará la posibilidad de realizar algún tipo de trabajo remunerado, que les permita contar con ingresos propios, en orden a cubrir gastos, personales, de transporte, etc. Consideramos muy conveniente alentar el espíritu y algunas formas concretas de la comunión de bienes, como por ejemplo la constitución de un fondo común solidario.

En la medida en que esta comunidad -seminaristas y el sacerdote formador-, ofrezcan diversos servicios pastorales a la parroquia, ésta podría ofrecer, de acuerdo con sus posibilidades, algún tipo de reconocimiento económico (como por ejemplo, asumir el pago de la factura de luz) que sería, al mismo tiempo, una valiosa colaboración con la experiencia.

\section{Seminarista del último año conviviendo con el párroco}

En el caso del seminarista que comparte la vida del párroco, normalmente la parroquia que lo reciba se hará cargo de los gastos habituales de la casa parroquial, como los servicios y la alimentación.

Por las mismas razones, no sólo económicas sino también formativas, que se aludieron en el parágrafo anterior (referido a la comunidad formativa en parroquia), se procurará, según las posibilidades y atendiendo a cada caso, que el seminarista provea, total o parcialmente, a sus gastos personales (como los de transporte, materiales de estudio, etc.), mediante algún trabajo remunerado que pueda realizar.

Al acordar la realización de esta experiencia en una determinada parroquia, será importante abordar, desde el principio, el tema del sostenimiento económico, y establecer, con la mayor claridad posible, los términos y la modalidad en que se expresará concretamente la colaboración 
entre la comunidad parroquial y el Seminario. Tendrá que ser el fruto de un discernimiento compartido, entre los formadores, el párroco y el mismo formando, que tenga en cuenta las peculiaridades de cada situación, junto con los criterios de la corresponsabilidad y solidaridad eclesiales que han de animarnos a todos.

En caso de ser necesario, desde el economato del Seminario se brindará la ayuda que se requiera, tanto por parte del seminarista como de la parroquia que lo acoge, en espíritu de comunión efectiva, a fin de que la experiencia no sufra menoscabo por dificultades de orden económico.

\section{LA FORMACIÓN INTELECTUAL}

Hasta aquí el proyecto cordobés.

Sin querer intentar una programación de los estudios, sería bueno tener en cuenta algunos valores y contenidos transversales que vayan dando sentido a las diferentes etapas formativas.

a) En una primera etapa de orientación, ayudar a que los futuros ministros realicen una lectura de los signos de los tiempos, mega tendencias, plan de Dios sobre la humanidad, juicio profético sobre la realidad, respuestas de la Iglesia, grandes opciones pastorales...

b) En una segunda etapa de iniciación, ayudarles a realizar unas reflexiones sobre las corrientes del pensamiento contemporáneo, de las diversas religiones, doctrina social de la Iglesia. La Misión de la Iglesia en el mundo, antropología cristiana, la realidad en la familia, la política, lo social, la economía. En general la relación de la Iglesia con el mundo actual. Esta reflexión debería estar acompañada por una experiencia pastoral en lugares más conflictivos: cárceles, hospitales, lugares de detención de jóvenes, emigrantes, desplazados y también contacto con la vida contemplativa.

c) En una tercera etapa de profundización, ir buscando una mayor comunión eclesial. Estudiar las asignaturas que tienen relación con la pastoral práctica: catequesis, familia, pastoral juvenil, pastoral vocacional, pastoral de niños y adolescentes, etc. Profundizar la cosmovisión conciliar desde la óptica de la unidad y de la comunión. Iglesia comunidad de ministerios y de servicios. Unidad de misión con diversidad de carismas y servicios. Profundizar en las corrientes culturales, filosóficas y religio- 
sas. El problema del ecumenismo. La pastoral vista desde los diferentes:

- Comunidades

- Sectores

- Servicios

- Ministerios

- Estructuras

\section{LA ESCUELA DE TEOLOGÍA DEL SEMINARIO DE PARIS}

Ya van a cumplirse veinte años de la experiencia del Seminario de París promovida por el Cardenal Lustiger. En la presentación que el Cardenal hace de esta experiencia de Seminario llama la atención el sentido que están dando al estudio de la teología:

\section{La fe de la Iglesia}

"Se trata de introducir a los estudiantes en una reflexión sobre la Iglesia y de situarlos dentro de ella". "Este estudio fortifica el amor de la Iglesia que es testigo de la Verdad y favorece el compromiso apostólico al servicio de los hombres. El futuro sacerdote estará de esta forma mejor preparado para comprender las cuestiones de hoy día y afrontarlas. El estudio de la filosofía es igualmente importante, aunque resulte un tanto difícil para la mentalidad tecnológica de los estudiantes de este momento. Esta es la razón por la cual ciertas cuestiones filosóficas son propuestas al final del "currículo teológico.

\section{La escritura leída en comunidad, centro de la teología}

"El estudio no puede reducirse a una mera acumulación de conocimientos. Pide una integración permanente en el interior de la fe para captar y comprender lo que Dios revela en Cristo a la Iglesia, de tal manera que progresión intelectual y madurez espiritual vayan unidas".

Estudio de la teología es también un itinerario de libertad. Ella lleva al estudiante a comprometerse en la fe. La via espiritual se enriquece con esta confrontación.

La mutua confrontación conduce a recibir esta Palabra no solamente según las circunstancias de la vida de cada uno y de su propia sensibilidad, sino en la fe de la Iglesia. 


\section{El método de los seminarios de trabajo}

El estudio ha adoptado el método de los seminarios de trabajo, ya practicada desde el año 1968 por el Instituto de estudios teológicos de Bruselas, estos estudios favorecen la reflexión en común.

Bajo la dirección de varios profesores, ellos desarrollan trabajos en grupo, exposiciones hechas por los estudiantes y debates. Estudiantes y profesores de esta manera son invitados a escucharse los unos a los otros, a buscar y a progresar unidos en el respeto mutuo. Este método es decisivo para responder a unos jóvenes que vienen de una cultura donde se relativiza todo y se discute todo, a veces de manera irresponsable. El debate es normalmente una confrontación con la Palabra de Dios. El debate es la búsqueda de la verdad. En la que todos colaboran en la búsqueda de la verdad. Además, cada tema es trabajado con tres o cuatro profesores. Así la unidad de la fe es presentada desde distintos puntos de vista. Así se arraiga el sentido eclesial de la teología.

Cada semestre hay tres seminarios:

1. Escritura: propone la lectura continua del libro de la Biblia.

2. Escritura y tradición: para comprender de qué manera la fe de la Iglesia interpreta la escritura.

3. Discernimiento teológico: debate sobre una cuestión actual.

Estos seminarios han suscitado grupos espontáneos de reflexión en las casas del seminario de París.

Los estudiantes tienen edades e itinerarios muy variados que hacen imposible obligarles a que todos sigan el mismo programa de estudios. Por eso, según normas académicas precisas, cada estudiante busca cada semestre, con la ayuda de su tutor los seminarios y cursos que seguirá. Las ofertas superan las materias que cada estudiante puede elegir. Es una forma adecuada de formar en teología a gente adulta.

\section{Los profesores y tutores}

Este programa de estudios exige un gran número de profesores. La gran mayoría desempeñan un ministerio y representan todos los estados de vida (sacerdotes, religiosos, religiosas, laicos).

Lo más importante es que cada profesor, aunque sea especialista, no se aísle en su competencia exclusiva. Los programas los elaboran varios profesores en colaboración, en grupos de tres en tres. Gracias a esta colaboración los alumnos tienen la sensación de aprender una sola ciencia. 
Cada estudiante es ayudado en su itinerario intelectual por un tutor con el que puede cambiar opiniones, un acompañante intelectual que le ayuda a encontrar el método preciso y que le aconseja en la elección de las más apropiadas para él. Cada quince días, los tutores e reúnen para evaluar, eventualmente rectificar, la trayectoria de un número preciso de estudiantes. Se trata pues de una tutoría colegiada que invita también a los profesores a trabajar unidos.

Esta pedagogía personalizada permite que el tutor que elija las materias que pueden responder a las cuestiones que trabajo pastoral que realiza el alumno le va provocando. El estudio de la teología toma así plenamente parte de la misión pastoral de la Iglesia.

\section{La confrontación de vocaciones diversas}

En el Estudio, los seminaristas estudian junto a otros estudiantes, candidatos al diaconado permanente y diáconos permanentes en formación continua, religiosos enviados por su Ordinario, religiosas en formación o laicos y laicas con justa motivación. Así se evita la clericalización.

\section{Las casas del seminario de París}

La forma de vida difiere un tanto del modelo Cordobés. También tiene un único rector. Pero son varias casas que forman una especie de campus y que aglutina varias viviendas que pertenecen a parroquias a iglesias o parroquias muy próximas a Notre-Dame. Los seminaristas de los primeros años viven en casas parroquiales a fin de que conozcan la vida concreta de una parroquia, hacen tareas apostólicas, pero respetan el tiempo necesario para sus estudios. En los seis años de estudios hacen un retiro de mes y un viaje de mes a Israel para leer la Biblia en el terreno.

El modelo monástico del seminario tridentino no resultaba eficaz. El grupo pequeño exige una vida comunitaria más profunda donde no resulta fácil encubrir el carácter, la capacidad de relación, etc.

Son muchas casas, pero un solo seminario. La unidad se apoya en la unidad espiritual y teológica del Estudio. La presencia de los seminaristas en medio de la ciudad recuerda al clero y a los fieles una de las prioridades del pueblo cristiano: que de ellas nacen las vocaciones para sacerdote. Ha contribuido también a remontar los conflictos generacionales.

Este modelo del campus urbano ha permitido esbozar una solución a la dificultad de la formación en vistas al sacerdocio, en una cultura secu- 
larizada, en un aprendizaje práctico que pone a los seminaristas ante las situaciones pastorales más variadas.

\section{COMENTARIO FINAL}

Soy consciente de que hay muchas experiencias similares a este proyecto de la Arquidiócesis de Córdoba (Argentina). Me parece que conocer estas experiencias puede ayudar a un enriquecimiento mutuo. El Seminario Tridentino necesitó siglos para ir adquiriendo su perfil, nunca acabado. El Seminario del Vaticano II creo que debe estar perfilándose permanentemente.

El equipo formativo, la comunidad educativa del seminario, que no está integrada solamente por los "formadores", va proporcionando a los seminaristas un cúmulo de experiencias que les permiten discernir la vocación y responder a ella adecuadamente. En permanente diálogo con cada seminarista lo van ayudando a crecer como persona, como discípulo de Cristo, pastor de la comunidad.

- El rector, asegura la unidad de la comunidad del seminario y el vínculo con el obispo y la comunidad diocesana.

- El padre espiritual personaliza el proceso formativo para cada uno de los candidatos, mediante actitudes de caridad pastoral, que acompañan, estimulan y ayudan al discernimiento vocacional.

- El coordinador de pastoral programa, implementa y evalúa las prácticas pastorales.

- El director de estudios coordina las actividades académicas de tal manera que contribuyan al logro del objetivo fundamental del seminario: formar pastores.

- Los profesores en su cátedra cumplen una auténtica misión pastoral en la formación del futuro pastor.

El desafío es la formación de pastores apóstoles, con espíritu misionero, que sean capaces de evangelizar en profundizar el ambiente en el cual vana estar situados y, si es el caso, ir más allá de las fronteras diocesanas.

La Iglesia y los seminarios, manteniendo lo esencial, han de ir acompañando el proceso de transformación de la sociedad y de los jóvenes. El Vaticano II quiso entrar en sintonía con el "hombre moderno". Al termi- 
nar el concilio ya apuntaba otra problemática que era la del hombre "postmoderno". Seguro que cuando tengamos respuestas más o menos adecuadas a esta situación, las nuevas situaciones nos presentarán nuevos desafíos a los que habrá que responder con nuevos paradigmas de seminario. Ojalá sean elaborados la seriedad y reflexión. El proyecto cordobés presenta la última etapa de la formación inicial. Me imagino que ya estarán proyectando las otras etapas anteriores en la misma línea de formar pastores para una Iglesia comunidad de ministerios y carismas. 